\title{
Quasi-Incestuous Paliyan Marriage in Comparative Perspective
}

\author{
Peter M. Gardner*
}

Department of Anthropology, University of Missouri, Columbia, MO 65211-1440, USA

\begin{abstract}
Quasi-incestuous marriages of South Indian Paliyan foragers are described and compared with broadly similar arrangements in nine other cultures. Twelve percent of Paliyan marriages occur through pedogamous union with step- and adopted children, some calling this their preferred form of marriage. Paliyan subsistence, households, types of marriage, and pedogamy are described. Although two sample cultures exhibit more aversion to sex in quasi-incestuous marriages than Wolf's revision of Westermark's incest theory would predict, the 10 culture comparison suggests that the unions in question may best be looked at as: (a) ways for elders to control marriage to protect family resources, (b) contingency arrangements in tightly structured systems, or (c) products of individualized decision making in loosely structured, un-coercive systems.
\end{abstract}

\section{INTRODUCTION}

In several cultures, scattered across four continents and Oceania, it has been possible in the recent past to marry stepor adopted children, wed adopted siblings, or enter into a plural marriage (or sexual relationship) with the parent or child of an existing spouse. These are rare and exceptional arrangements in a few of the cultures; they are common and even preferred in others. The societies differ greatly in scale, in form and tightness of social structure, and in economic specialty -- plough cultivating (Karaikkat Vellala of south India, Chinese of southeast China and Taiwan, Tibetans of Nepal), herding (Tibetans, Hima), swidden cultivating (Garos), fishing and gardening (Marquesans), foraging (Paliyans, Wadadika Paiutes, Kaingang), and herding/foraging/ gardening (Diné/Navajo). Given all these variables, we should not be surprised to find that more than one theory may be needed to account for the customs in question.

The first section of the paper will describe the child marriages of Paliyan foragers of south India. In the 1960s, many Paliyans held that adopted and stepchildren were the preferred spouses and, in forest-oriented groups studied, at least $12 \%$ of the unions were found to be of such a form. Paliyan stepchild marriage was mentioned at Man the Hunter conference in 1966, but it was labeled by an older term, "gerontogamy." "Pedogamy" was coined about 1968 and a brief, preliminary description of Paliyan practices appeared in two publications $[1,2]$. The new term was introduced because, while "gerontogamy" is denotatively appropriate in Australian society, in Paliyan society "pedogamy" is more accurate. For it is not the advanced age of the senior party so much as the youth of the other which is distinctive. Indeed, the senior partner may only be twenty to thirty years old. The present, expanded account of Paliyan pedogamy is based on exhaustive examination of genealogies and field notes from an

*Address correspondence to this author at the Department of Anthropology, University of Missouri Columbia, MO 65211-1440, USA; Tel: (573) 2680123; Fax: (573) 884-5450; E-mail: gardnerp@ missouri.edu 18-month general ethnographic study. It covers previously unconsidered data, it incorporates a few minor corrections, and it employs new forms of analysis. To better understand the pedogamy of Paliyans, their subsistence economy, sociopolitical structures, and marriages in general will be examined. Finally, their pedogamous marriages as such will be described.

The second section of the paper will be a comparison of Paliyan practices with some close counterparts elsewhere. These are: (a) a culture in which it was very common for a boy's family to adopt a baby girl with the intention of raising her to be the boy's marriage partner; (b) five cultures in which a person could enter into polygamous marriage with a parent and child and, in one of the five, it was also possible to adopt and bring up a girl, then marry her; and (c) three cultures in which certain individuals were permitted occasional or regular sexual contact between parent- and childin-law, and, in two of those cultures, between brother- and sister-in-law. Because, in many of the cultures, unions are with persons previously called parent, child, parent's child, spouse's child, child's spouse, and so on, recent perspectives on incest will be brought into the final discussion [3-9]. Finally, all ten cultures will be examined to ascertain underlying factors that might permit their quasi-incestuous arrangements.

The author conducted general ethnographic field research on Paliyans during 1962-64, with a brief follow-up during 1978. The goals of the original study were dual: (a) to describe the culture comprehensively and (b) to understand how and why the foragers managed to maintain their aloofness from the adjacent Tamil civilization for some two millennia. While study of marriage was integral to the project, it was not a special focus of attention. At the time of the study, an estimated population of 3300 Paliyans was found along the lower, eastern slopes of India's southernmost ranges. They lived in small (18 to 30 member), scattered bands in relatively dry monsoon forest and in forest-edge settlements (with 25 to 60 , or even 80 , members). 


\section{PALIYAN CULTURE}

The economy has been described in detail elsewhere [10, 11]. For present purposes its salient features are few. Both sexes collect wild yams (which constitute about $80 \%$ of the diet by weight), both sexes fish, and, in the smaller bands, both sexes also hunt or collect small game. While, especially in larger bands, there are gender biases in some of these tasks, it is generally the case that people who reside alone suffer no lack of basic nutrients. Indeed, it is usual to see several widowed or divorced elders living alone in any given band. They subsist comfortably on the basis of their own labors and are able to remain fairly autonomous unless infirm with age. It is also feasible for a family to manage adequately on the labor of a single mature adult. Although men are more involved than women in sporadic contract labor for outsiders (collecting honey, medicinal plants, and other forest products; working in plantations or fields; and so on), household gender economics of such part-time laborers are not greatly different from those who focus on foraging.

Paliyan socio-political life is affected deeply by a master principle, that individuals make their own decisions. Rules and tradition per se have little authority. One never hears them saying they do something "because it is correct"; only occasionally one hears "because it is our custom" (for instance, one person did say this about pedogamy). Paliyan behavior is shaped as much by personal considerations as by rules. In residence choices and marriage arrangements, especially, their exercise of individual judgment lends fluidity or looseness to social organization.

Forest Paliyans believe that a couple, or a lone individual after the age of discretion, can and should exercise independent choice over such matters as movement and residence, creating the possibility of neolocality. But, Paliyans greatly prefer living near primary relatives; they speak especially of being near mothers or siblings, and, late in life, near grown children. A husband and wife who come from different bands may move back and forth between their respective groups, with one of them taking the initiative and the other following along. Or, grown siblings may move to a new band together. The general outcome has been shown to be balanced bilocal residence [2].

A third of all forest Paliyan households are what Kolenda calls "supplemented nuclear families" [12, p. 147], these being formed when: (a) people of advanced age, especially widowed women, live with their children's families; (b) youths join married siblings, particularly when orphaned; or (c) young newlyweds stay on temporarily with the parents of one of them. But such households only form when there are mutual feelings of closeness. Extended households may exhibit considerable coordination in work and play activities, yet their work practices and disposal of the fruit of each person's labors reveal that, beyond the nuclear family, participants usually work parallelly rather than cooperatively. The emphasis is on self-reliance except for sporadic periods of mutually beneficial activity, such as fishing together, and helping with infant care. The main ties are companionship with those one trusts. Only people who are truly unable to deal with their own needs are permitted to be dependents. Even so, dependence is usually partial. It was only in the case of a very old woman that the additional party was seen to be fully reliant on others.
As should be clear, Paliyans can be said to live in a state of anarchy. Because people make their own decisions, there is no such thing as a household head or a band head. A husband and wife have no authority over one another and they have virtually nothing that could be called authority over their children. The children are certainly cared for when young, but a child of four will not be told to keep away from a fire or a sharp tool, a six-year-old can move to another house without parental permission, and no one "owns" anyone else or has a right to define that person's behavior.

\section{PALIYAN MARRIAGE}

Although wedding ceremonies are seldom celebrated, a clear distinction can be made between Paliyan marriages and affairs. Marriages are public and the affairs that punctuate most life histories, while visible, are furtive. It is quite frequent, especially in first partnerships, for a union to be solemnized with an exchange of betel leaves and salt and a promise of lifelong fidelity. Even if it endures but a few days, a public union, with or without such ceremony, is considered a legitimate marriage. One elderly man had entered into all five of his unions without ever having had a wedding. Marriage is also optional and, while most adults at any given time cohabit and cooperate economically with a member of the opposite sex, the economy permits them to live comfortably as single persons. Many divorced and widowed individuals do, indeed, refrain from remarriage $[2,10]$. The economy also makes it possible to wed immature partners. Some 95 percent of marriages are monogamous. Paliyans say they give preference to marriage with contakaarar (members of a fuzzy set of their closest consanguines and affines) and about 35 percent of their marriages in the forest are indeed with very close relatives.

Some marriages are reputed to last for life; the usual situation, however, is one of fragile, often serial, unions. In the name of peace, unions can and should be terminated quickly by the offended parties when conflict arises [13]. Broken marriages are commonly resumed after a matter of days; some are reestablished only after one or more intervening unions. When interviewed, people often ignored or forgot about such interruptions in their own marital histories and they seldom knew each other's in any detail. Twentyfive mature adults aged 26 or more on whom I had relatively complete data recalled a total of 60 unions, for a mean of 2.4 remembered marriages. One extreme case was a 35-year-old man who had 13 marriages with nine women. Also extreme were two women who were both too young for inclusion in the sample of mature adults: a 24-year-old who had been married six times to five men and a 15 -year-old who had already entered into a total of eight unions with three men.

Although the incidence of plural marriage is low, a review of those plural marriages helps to provide an understanding of Paliyan social processes. In addition, it gives us our first glimpses of pedogamy in context. Polygyny, polyandry, and a linear group marriage that combines the two forms of polygamy have all been noted.

Polygyny is the most common type of plural union. Three examples were recorded: one from a written account that is too brief for analysis [14], one from about the 1930s, and one on the basis of firsthand study. The second example 
appears to have been of brief duration and precise detail was hard to recover: Cuppan, an elderly man with an aging wife, adopted a girl in order eventually to form a pedogamous union. There was enough overlap of the two marriages for them to be recalled by grandchildren as polygynous. The third polygynous household could be studied directly and in detail as changes occurred. It involved four sisters who were married off and on, sometimes two at a time, to Catayan. The women had a joint household when living as co-wives and shared fairly equally the responsibility for household tasks and food procurement. They appeared to cope with each other harmoniously. Reasons for their coming and going were not always apparent; three departures I could account for had to do with a problematic employer, a lover, and one wife allowing her younger sister be the woman of the moment. I also watched one woman effectively get her older sister re-involved as a co-wife.

There was one case of simple polyandry, involving Raaman, Lacmi, and Kritnan. Lacmi had been a small girl and orphaned when Raaman adopted her. He brought her up to be his wife. At the time of my observations Raaman was 56 years old and weakened by what was probably Hansen's disease. Lacmi (by then 28) brought the second man, Kritnan (age 20), into their household during the field study. Although Raaman admitted privately that he disliked the new arrangement, he was accommodating. I even observed him sleeping outside on occasion, leaving his house to the younger couple. Raaman told me "I don't want to leave her to another completely. If I have caught hold of a branch, I should not leave it." When Lacmi cooked, she, did so for both men and limited cooperation grew up between the men themselves, with Kritnan sharing food he had brought in.

A single case was recorded of group marriage. Usually it looked like two households, spatially and economically -Viirappan living with 32-year-old Lacmi and, next door, Cuppiya living with 20-year-old Lacmi. Closer study revealed a secondary relationship between Cuppiya and the older Lacmi that entailed both reproduction and a measure of economic help. For a few weeks, Cuppiya was even found living in Viirappan and Lacmi's house. Lacmi (32) had been taken in as an orphan by Viirappan and brought up as his wife. Her oldest child was thought to be Viirappan's and Viirappan was raising as his her two younger children, whom Lacmi believed to have been Cuppiya's. But in this case the men did not cooperate economically. Cuppiya's main contribution to senior Lacmi was seen to be occasional food and jewelry. Relations among the four and with their near kin were peaceful, Cuppiya's sister, for instance, being noticeably friendly and supporting toward 32-year-old Lacmi.

What accounts for plural marriage? In both the simple case of polyandry and polyandry within the group marriage, a woman remained in economic and residential union with an ill partner who brought her up, while enjoying stable and publicly acknowledged sexual relations with a younger man as well. The original husbands resented these long-term arrangements, but they tolerated them so as not to insult and lose their wives. It was also noted that, in each case, others termed both men "husbands" and unhesitatingly traced their ramifying kinship relationships through either union as if it was a marriage. As for polygyny, Catayan attributed his pur- suit of new spouses to his lack of children and others agreed about his motives.

Given the fragility of Paliyan marriages, treating social relationships with care is surely the key to forming and maintaining plural unions. One person in each of the plural marriages served the community informally as a conciliator, as a person whose soothing, diplomatic, or witty ways of speaking calmed or distracted others in tense situations. Even though all other Paliyan conciliators are monogamous and Paliyans maintain resolutely that the role of conciliator entails no "right" to be otherwise, the involvement of conciliators makes sense. Their success with plural marriages was a plausible function of the very social involvement, diplomacy, or playfulness that qualified them to serve voluntarily as conciliators. It took a skilled person to set up and then maintain such an arrangement. Any misunderstanding would fragment it. It is patently clear that Paliyans are free to form marital arrangements of their own design so long as no one who is directly involved is offended or left feeling that personal rights have been violated.

In view of the Paliyan preference for close marriage, the pool of appropriate and available partners is small. This situation is eased slightly by age difference being no impediment to marriage. Out of 29 forest couples for whom I have careful relative age estimates, there was only one couple in which partners were about the same age; in 19 couples the husband was three to 35 years older (mean age difference $=15.5$ years) and in nine couples the wife was two to 41 years older (mean age difference $=13.6$ years). These figures demonstrate that large age differences between spouses are tolerated. It is worth asking, nonetheless, whether Paliyans merely tolerate them or actively seek them out. The answer to this should be apparent if we examine what Paliyans hope to achieve in the way of affairs. A few are explicit about their amorous wishes, but all tend to signal them by openly and unselfconsciously gazing for minutes at a time at those whom they find attractive. Others pick up on what they are doing, making sexual intentions unusually public. Youths in particular were sufficiently amused by the practice that corroboration of my own hunches became possible. All six men and three women on whom there is relevant data hoped to have affairs with one or more younger people. Men literally had their sights on women averaging 17 years younger than themselves and women were eyeing men averaging 21 years younger. Numbers are small, but they are consistent with each other and they accord with the figures on marriage.

Four of the 29 unions just examined were once pedogamous -- marriages that grew out of stepparent/stepchild relationships. This was considered by some to be a desirable type of marriage. In a wider sample of five forest bands, at least 18 out of 153 past and ongoing marriages were of this type (this is a correction of a figure published earlier [2]). To use the Paliyan idiom, 13 involved "bringing up" girls and five involved "bringing up" boys. It was not everybody's preference, but some who had options made deliberate plans for it. Further confirming the pattern, in the sample of 153 marriages there were a few unions with former spouses' post-pubescent children, and yet others with unrelated youthful partners. Although such youths were slightly too old for their marriages to have met my working definition of pedogamy, a few Paliyans did refer to these youths as having been 
"brought up," the same term employed when partners had lived together initially as parent and child.

Pedogamous unions were formed in two ways. The first way was for youngsters to be adopted at about five to ten years of age (one was still an infant). Each made a gradual transition, without any ceremony, from the status of son or daughter to that of husband or wife a few years later. Although some said that marriage was an explicit goal from the very outset, it was usually only after the transition that anyone referred to the relationships as marital. Given the informality of the change, sexual relations were sometimes initiated before parent/child kin terms were given up; they were usually begun about the age of puberty. A few of the children, especially younger ones, were orphans. A case was mentioned earlier of Cuppan adopting a girl with plural marriage in mind. What might have been a similar case in the making involved 65-year-old Muttamma. When she was about 50 she adopted her deceased younger husband's 9year-old brother, Alakar, then married him approximately 5 years later. At age 65, she adopted Ponnaiya, Alakar's older brother's 8-year-old son. When she was teased lightly once by an outsider about adopting Ponnaiya with polyandrous intentions, Muttamma denied that she planned plural marriage. The field study ended before her words were put to a test.

The other way of establishing pedogamy was marrying the child of a former spouse. This could either be done incidentally, after marriage with the child's parent had ended, or in a planned fashion, as in two of Nabokov's novels $[15,16]$, union with the parent having been a means for expediting the real goal. In one valley, out of a population of 61 , there were three simultaneous cases of men courting mother and daughter pairs. These appeared to be Lolita arrangements in the planning because each man's chief focus was on the daughter. Marrying the mother, if it could be achieved, would create eventual possibilities for marrying the daughter. Several of us thought that KaNNiamma, a married woman of 54 in the same group, envisioned precisely the opposite arrangement. When she began to foster interest between her daughter, Cellamma, and her own youthful former lover, Poonnan, it appeared as if she was using her comely, maturing daughter as bait. If she kept 20-year-old Poonnan nearby, KaNNiamma had an opportunity to reestablish her own relations with him. It should be noted that KaNNiamma was an active person who, without being offensive or pushy, did much to shape her own circumstances. She enjoyed a stable marriage with a man of 38, also called Poonnan, whom she had brought up, and it was also well attested that she had occasional affairs (one probably qualifying as a brief marriage) with much younger men, such as 28 -year-old KoTTe.

For adults, the advantages of marriage with the young were expressed in terms of sexual satisfaction and malleability -- such partners can be "brought up to behave properly." Experienced people hinted that compatibility and harmony were more certain where marriage was built upon the foundation of a parent/child relationship -- harmony being a pressing desideratum. Where it is possible to make an estimate, pedogamous unions did have above average durability, bearing out the judgment of the contracting parties. Estimates were possible for 14 of the 18 marriages: 11 were lasting ( 8 of these were ongoing) and only 3 were short lived.
One key consultant volunteered the idea that pedogamous marriages provided economic insurance for the aged, but, planned dependence being antithetical to Paliyan values, it is understandable that open acknowledgement of thought along such lines was rare. While pedogamous arrangements look loose and chaotic, both actions and words suggest that a major goal of south Indian foragers is stability and order.

For youthful partners, the advantages of pedogamy were less obvious. It can certainly be said that they were treated attentively and respectfully. Orphans in particular spoke appreciatively of their early marriages, giving the impression that they had felt care. Paliyans who worked seasonally at plantations or for forest produce contactors brought home purchased treats for their children when they could, and I saw young partners indulged thus, too. But such gifts were occasional and they were never lavish; it is difficult to believe that they alone were sufficient to mold the relationships, even if intended to. One middle-aged plantation employee told me in a confused, sad way that, although he regularly brought savory snacks for his recently matured wife, and he brought them more regularly than most could afford, she continued to reject his sexual advances.

Respect for the younger partner was obligatory, coercion or abuse being totally out of the question. For one thing, social life was very public. For another, even orphans had to pass judgment on a proposed plan; no one had the authority to impose marriage on another person and no one could impose adoption on one who was past early childhood. The young were also free to walk out later without being asked to justify their actions. I learned of three youths refusing or promptly terminating pedogamous arrangements. Her relatives reported to me how, years before, tiny 8 -year-old $\mathrm{Ku}$ ruvamma said "no" to a proposed adoption. Peecci, after an intermittent start, walked out at age 15, saying that she did not want to be married to a man much older than her -- she had other plans. Finally, Rancittam ended a relationship immediately when her stepfather moved to transform a severalyear-old adoption (which she had accepted) into a marriage. Certainly, whatever interests youths had in pedogamy were unlikely to be sexual initially -- such arrangements generally being established years before youths felt their first adolescent infatuations. Deep interviews with children and youths would probably be necessary to establish with any certainty the bases for their consenting to pedogamy. Although Peecci did once voice objections to the age of a potential partner, Paliyans will probably make it difficult for us to elicit a corpus of meaningful and trustworthy data on young peoples' objections to potential pedogamous matches due to the marked cultural indelicacy of discussion of other people's shortcomings [11, pp. 89-90; 13].

When they started experiencing amorous feelings toward others, some of the young ended their pedogamous marriages and yet others interrupted them for affairs. Mature partners often had the perspective and patience to ignore these brief sexual adventures. Paliyans did not think of an interrupted marriage as a broken promise or contract. Many hoped for and anticipated long-term marriages, but there were no agreements that took precedence over each person's right to independent decision making.

Some clusters of related individuals were found to repeat pedogamous and other stepchild marriages for two or three 
generations. The most complex of these developed as follows: (1) Ciittai was brought up as a child by KaNapatti's father and married him. (2) After becoming a widowed adult, Ciittai brought up her stepson (KaNapatti), married him, and produced one child (Peecci). (3) Ciittai next brought up and married another boy, Cinkappan, then (4) she formed a union with a slightly older youth who happened to be her brother's son (Catayan). Finally, (5) Catayan married young Peecci who was, by then, his stepdaughter. Additional marriages of these individuals are omitted for the sake of simplicity.

Knowing that they tended to be relatively durable, we may still ask whether stepchild marriages were fertile. Afterall, many adult Paliyans expressed the desire for children. One woman married a youth at about the time of menopause. Fourteen other females in pedogamous unions had a total of 39 births, the mean being 2.8 births (in ten long lasting unions of this kind the mean was 3.3 births, and eight of the women who had completed their reproductive careers had a mean of 3.5 births). However, given the openness of Paliyan sex lives, we must not assume that all 39 children were the respective husbands' offspring. For instance, 32-year-old Lacmi lost 4 of her 7 children as infants and, of the 3 who survived, she herself attributed but one to the husband who raised her. Women who were not involved in pedogamous marriages were of similar ages to those who were married thus and, again, about half had probably not completed their reproductive careers. They averaged nearly 4.5 births at the time of my study. While the number of subjects is very small, the figures show a reduction of fertility with pedogamy. And, we should note at least one case of attested sexual aversion -- the young woman mentioned above, who consistently rejected her husband's advances.

\section{A COMPARATIVE PERSPECTIVE}

The nine cultures being compared with Paliyans are structurally and functionally diverse. Although some cultures are broadly similar enough to one another in their marital and sexual arrangements that they can be dealt with in groups, one culture, the first to be described, needs to be treated separately.

\section{Adoption of a Bride}

In southeastern China and Taiwan, adoption of a child was the usual way of bringing a bride into the family. Prior to about 1950, in the so-called "major" or proper marriage of China, a bride entered her husband's family as a young woman; in the "minor" and less proper marriage, she came in as an infant or child. A. P. Wolf has traced English language mention of such minor marriage back to the $1860 \mathrm{~s}$ [17]. The Chinese terms, t'ung-yang-hsi ["daughter-in-law raised from childhood"] and sim-pua ["little daughter-inlaw"], both referred to a girl who was adopted then brought up by her foster mother to become a daughter-in-law. We should also acknowledge teng-lang-hsi ["a bride waiting for a groom"], that is, a girl adopted by a family in mere anticipation of birth of a son [17]. According to some nineteenth and early twentieth century reports on southeast China and Taiwan, adoption of daughters-in-law used to be the main way of acquiring brides -- local and regional frequencies on the order of $41 \%, 70 \%$, and $80 \%$ being reported by anthropologists and a pre-revolutionary Chinese government minis- try $[17$, pp. $865-6 ; 18$, p.180]. The explicit rationale for the practice was reduction of difficulty between mother-in-law and daughter-in-law, and harmony between them was said by many Chinese to be essential for preserving a joint family $[17,18]$. M. Wolf holds that bride adoption entailed realistic planning by the mother-in-law. Her argument is plausible, because the timing of splitting of the Chinese family in each generation suggests that fission was a function of relations among women rather than being a result of competition among brothers, as previously thought [18, pp. 164-6]. Although bride adoption meant an improved chance for harmony among the women, it is said to have given rise commonly to feelings of aversion between husband and wife [17, 18]. And, the "minimal formalities" of their eventual wedding will have done little to ease the couple's feeling of awkwardness over their transition from siblings to spouses. M. Wolf has summarized divorce statistics for older people in one district of Taiwan: $24.2 \%$ of sim-pua marriages ended in divorce, compared with $1.2 \%$ of other marriages [18, p. 183].

\section{Polygamous Marriage to Parent and Child}

In five of the cultures -- Garo, Tibetan, Wadadika Paiute, Diné, and Kaingang -- we find that some people were married simultaneously to parent and child.

Garo are swidden cultivators atop hills between the lower Assam Valley and Bangladesh. Two kinds of first marriage were usual: (a) a couple chose one of their daughters to inherit their property and support them in their old age, they found her a husband, and the young couple lived uxorilocally; (b) other daughters selected their own husbands and, about the time of marriage, left home to live neolocally [19]. Because of the importance of relationships between intermarried lineages, there was emphasis on arranging prompt replacement marriages for widowed and divorced men and women. Yet Garos felt that widowers had "a legal right to demand a new wife" [19, p. 144]. And they thought that when a young man married a widow it was only fair that he be given a younger wife as well. A widow without a daughter had to adopt someone who could serve as the junior partner in her ensuing polygynous remarriage; however young the daughter might be, it was "usual for the man to be married to both mother and daughter simultaneously" [19, p. 148]. In a community with 70 married men, nine were married to widows as replacement husbands. Eight of the remarrying women brought jikgite ["young wives," either adopted or true daughters] with them, six of whom were old enough to be sexual partners. Simultaneous sexual relationships were apparent; for instance, one man had children of similar age by mother and daughter [19, pp. 149-50]. Burling noted two cases, though, in which a man was believed by others to be experiencing difficulty initiating proper sexual relations with his jikgite. In Garo sociology, if a man could not transcend seeing a young woman (who was, properly, his sexual partner) as a stepdaughter, it was thought that this would eventually lead the young woman to commit adultery or elope. He would then be the one blamed for the ensuing social complications [19, pp. 150-1].

Nomads in the high pastures of Tibet and settled Tibetans in Nepal have been undergoing recent change, including Nepalese legal changes that limit the extent of polyandrous 
arrangements. But two early descriptions suggest that they occasionally entered into plural marriages that crossed generations [20, 21]. Monogamous families were clearly in the majority, but the overall range of marriage types was considerable: monogamy, an unstable type of fraternal polyandry, avuncular polyandry, sororal polygyny, and non-sororal polygyny. The early accounts are too fragmentary to summarize clearly. We can say that Tibetans had patrilineal clans. And, whether they lived in tents or houses, inheritance and management of property figured centrally in the organization of households. Ekvall offers a capsule description of a "rather rare mother-daughter form" of polygyny among nomadic Tibetans, for whom ownership of livestock lay with the tent/household. If a family had just female children, it could bring in a son-in-law as a surrogate son. He took his wife's lineage name and remained in her family tent. Should the father die early, the mother and daughter became cowives of the in-moving male [20, pp. 26-7]. In the course of describing fraternal polyandry, Ekvall alluded, in passing, to "other arrangements, including father-son co-husbands" [20, p. 27]. We have better information on Bhotea Tibetans. Bhoteas had patrilocal residence. In a high altitude, 36-house village in Nepal, Kawakita noted one case of sororal polygyny and several of polyandry. Kawakita found people reticent about polyandry, yet he was able to identify three cases of fraternal polyandry and two apparent cases of chamadung [bigenerational polyandry] -- one each from the main village and a nearby hamlet. He summarized chamadung thus. A woman may have plural marriage with any of the following: her initial husband, then his younger brothers of descending age, then the oldest male in the son's generation, then the son's younger brothers of descending age, and so on [21, pp. 266-80]. This practice "takes even the form of paternal polyandry in which a father and his real son have a common wife, if the wife is not the son's real mother" [21, p. 272]. Both cases of chamadung that he encountered involved paternal uncle and nephew. As might be expected with polyandry, there was considerable difference in age between spouses. Kawakita tabulated age difference for 45 marriages: in 24 the husband was 1 to 13 years older, in 18 the wife was 1 to 22 years older [21]. Goldstein's subsequent study of refugees from one central Tibetan village greatly clarifies the earlier picture. He found that property affects marriage. The Tibetans known as tre-ba ["taxpayer"], having corporate family units, allowed only one marriage per family to prevent partition of family property. Goldstein examined 62 marriages involving men with family property and, in the 32 families having more than one son, all marriages were polyandrous [22]. If a mother died when her eldest son was in his teens, remarriage of the father then marriage of the sons could lead to competition within the family, conflict, and partition of their property. The solution was for the father to find a young woman to marry the sons, but with explicit agreement that the father would have sexual rights over her [22, pp. 68-9]. Those Tibetans of the lower stratum, known as dï -jung ["small smoke"], were found to be monogamous except for a few who had become wealthy from trade [22]. Goldstein closed with the observation that "polyandry was valued as a technique for maintaining families intact, but as a form of marriage in and of itself it was considered inferior to monogamy" [22, p. 73].
Wadadika Paiute, foragers of the Great Basin, permitted simultaneous marriage to parent and child. Whiting found that they reported much polygyny, particularly among men with prestige. Frequently men married sisters, "as it is said that they do not fight." In addition, there were "several cases of a man married to a mother and daughter." One man married his wife's mother and cousin and another "courted the daughter and was forced by the mother into marrying her as well" [23, p. 100]. Further details on their marriages are not given.

Although the Diné (or Navajo) Tribal Code forbids their once-common polygyny, it remains socially approved in isolated communities. The most common forms are, first, sororal polygyny, then, stepfather-stepdaughter marriage [24, p. 181]. Shepardson and Hammond examined present day cases of the latter. One man was married to a mother and daughter; another was married to two sisters and the daughter of one of them. Women often figured in making these arrangements. Several wives, on aging, brought daughters from earlier marriages into the union, but, in two cases, men marrying women who were pregnant by other men, found their plans to marry stepdaughters at puberty were foiled by their wives [24]. Aberle, reviewing early sources, noted evidence that older women often used stepdaughter marriage "to hold a younger husband" [25, p. 122].

On account of their plural marriages with parents and children, Kaingang foragers of the southern Brazilian highlands have been grouped with the previous four cultures. In addition, they, like Paliyans, used to practice adoption with future marriage in mind. More will be said about that below. Based on Henry's description, it is possible to say that Kaingang resembled Tibetans in the diversity of their forms of marriage -- monogamy $(60 \%)$, polygyny, polyandry, and "joint" or group unions [26]. Even their polygamy with parent and child took diverse forms, for example: (i) a woman marrying three men then, when he matured, contracting a further polyandrous marriage with the first husband's son; (ii) another woman joining the group just mentioned (on the wife's invitation), wedding father, son, and the other two men simultaneously [26, p. 38]; and (iii) a man marrying a woman then, later, marrying her mother polygynously [26, pp. 41]. Note, also, a 30-year-old man losing his young wife, then having an open and protracted affair with his attractive, married, 50-year-old, former mother-in-law [26, p. 39]. There were limits to such arrangements. For instance, Henry found no cases of a man marrying his daughter-in-law. Although "older men preferred the comfortable security of joint households," young co-husbands tended to leave such households as soon as young women became available. And jealousy undermined some nascent plural arrangements. Henry suggested, nonetheless, that these marriages usually brought peace and cooperation in place of jealousy. "Cohusbands who had grown to maturity did not part. The strongest loyalties in such marriages were . . . among the men." Adoption with future marriage in mind was said to be "occasional," but Henry offered limited specifics. He did hear one woman speak thus about her eleven-year-old daughter: "'Take her and bring her up,' she said. 'When she is grown, marry her, and she will keep house for you'" [26, pp. 42-3]. 


\section{Legitimate Sexual Contact with In-Laws}

Certain brides in two cultures -- Hima cattle herders in southern Uganda, and Karaikkat Vellala (or Malayali) cultivators of the Shevaroy Hills in Tamilnadu, south India -- had regular and legitimate sexual contact across generations. And, in the Marquesas, there were similar but yet more complex possibilities.

Hima were patrilocal nomadic cattle herders of southern Uganda, who practiced an alternative to the polygyny that was usual in their region. Instead of using his cattle to become polygynous himself, a Hima man enticed his first-born and often just teenaged son into youthful marriage "to control him, and to ensure his continuous participation in the camp's work." The father provided the cattle to support his daughter-in-law, he was appointed her guardian, and he, as supplier of the bride-wealth, had sexual privileges. Indeed, if the groom was not yet capable sexually, his father "could substitute for him sexually for some months or even longer" [27, p. 188]. Although a junior son could not expect such early marriage, at puberty he was "allowed to make love to his sisters-in-law and step-mothers" [27, p. 190], as also among the Shilluk [28]. There was an economic side to this. Only men could milk cows and milk could not be stored. If a husband was ill or was absent for over 12 hours, a kinsman, friend, or neighbor had the duty to milk for him and feed and protect his wife. Doing this "conferred" on the helper the right and privilege of being the wife's lover. And, lovers who were not the husband's agnates became "quasi-agnates" in the process [27, pp. 183-5]. Elam held that men linked themselves to other men thus and he quoted one groom who greeted his new bride with this warning, "You find a big camp here, do not make it small! We cannot and should not isolate ourselves from people of this camp and remain here just you and I!"’ [27, pp. 192-3].

Thurston described marriage practices of Karaikkat Vellala, peripheral Hindus of the Shevaroy Hills thus:

The sons, when mere children, are married to mature females, and the father-in-law of the bride assumes the performance of the procreative function,.... When the putative father comes of age, and in their turn his wife's male offspring are married, he performs for them the same office which his father did for him [29, pp. 49-50].

Direct information from a member of the community indicated that, with changing times, the bride had become free to choose for herself those who could perform the procreative function [29]. Thurston and Rangachari repeated use of the material [30] and gave a similar sketch of Konga Vellalas, cultivators on the adjacent plain who were said by tradition to be related to Karaikkat Vellalas and who, accordingly, will not treated as a separate case. Konga Vellala males prefer mother's brother's daughter marriage.

To such an extent is the preference for such unions carried out, that a young boy is often married to a grown-up woman, and it is admitted that, in such cases, the boy's father takes upon himself the duties of a husband until his son has reached maturity, and that the wife is allowed to consort with anyone belonging to the caste whom she may fancy, provided that she continues to live in her husband's house [31, p. 418].
This second account provides a possible explanation for the practices of both groups, namely, that they are contingency arrangements.

Finally, Marquesan marital and sexual arrangements were complex. First, Handy reports that it was preferred that marriage partners be closely related, best of all as crosscousins, "in order to keep all the property of each within the family" and in order to meet certain ritual requirements. Secondly, Marquesans had plural marriage. Not only was it usual for women to have secondary husbands, a few men had secondary wives. The purpose of polyandry was said to be creation of a large male work force within the household. One sequence by which it came about was: (a) betrothal of two young people during early childhood or even before birth; then, years later, (b) marriage of the young woman to another man, of her own choice; finally, under family pressure, (c) marriage of the woman to her originally betrothed [32, pp. 98-103]. Linton [33] reports two or three men to one woman being "usual" in a household, "while in the household of the chief there might be eleven or twelve men to three or four women." "The basis of the [prestige] grading rested primarily in man power." And men were "rewarded for good service" by a night's sexual access [33, pp. 152-5]. The household head ran things and distributed favors, although it was to his advantage to see that his underlings were sexually satisfied, so that they would work for his house and not wander off with other women. This was a delicate matter because participation of a secondary husband was voluntary and, in ordinary households, so too was that of a woman who had been married without formal ritual. Both were free to leave at will [33, p. 158]. Third, there were possibilities for "temporary or occasional cohabitation" between motunoai [husband's or wife's parent] and hunona [son's or daughter's spouse]. These relationships were described "by the phrase $e$ koana $i$ te kamo, literally 'to be permissible to steal,' the sense being apparently, that one could snatch such temporary relationship (sic) if occasion offered." A man also "had the right to sleep with his brothers' wives or with his wife's sisters with the consent of their husbands ...." And, in these same-generation relationships, "permission appears to have been given only when the ahana [husband] was absent" [32, p. 99].

\section{DISCUSSION}

\section{Signs of Aversion}

Because the unions that concern us have their genesis within the household in all ten cultures, the next step might be to examine them in terms of the insights of incest theorists. Are we, though, dealing with incest? While the marital and sexual relations that are permitted (or imposed) would be considered virtually incestuous in many cultures, a biologist would find them incestuous only in a classificatory sense. For this reason, they are what Durham calls "noninbred incest" [7, p. 29]. Yet, social relations tend to be both complex and highly meaningful, and the nature of relations within the household can hardly be understood as a simple function of biological genealogy. Recent thought on incest deserves a look.

Decade by decade, fairly comprehensive reviews of incest theories have been offered by Murdock [3], Aberle et al. 
[4], Burton [5], Fox [6], Durham [7], Wolf [8], and Turner and Maryanski [9]. Although every review has ignored several theories, and some theories were occasionally lumped together, there are 12 distinct theories. They were not all held in the same regard. Notably, no one expressed great confidence in six of the 12 theories (generally labeled Socialization, Demographic, Instinct, Sociobiology, Neurology, and Primatology) and a single review took interest in each of four others (Family Harmony [4], Group Alliance [4], Psychoanalytic [6], and Synthetic [9]). It is only the two remaining theories that have been deemed particularly worthy of merit, especially in the most recent reviews. These are L. H. Morgan's [34] Inbreeding Avoidance theory [4, 5, 7- 9] and E. Westermark's [35] Aversion theory [5-9]. And two reviewers stand out for the depth of their work, Durham and Wolf. It is clear that, while Durham's detailed analytical review finds the Inbreeding Avoidance theory better explains the origin of the incest taboo, the Aversion theory also remains plausible in his judgment and it answers all five of his analytic questions [7, pp. 320, 360]. Wolf, who has substantial bodies of data on three well-studied cases, predicts that the Aversion theory "will eventually prove to be the best" [8, p. 171]. Of course, because we are dealing here with noninbred incest, the Inbreeding Avoidance theory may have less obvious relevance.

Wolf's data bear mention. Westermarck had said that "there is an innate aversion to sexual intercourse between persons living very closely together from early youth" $[35, \mathrm{p}$. 320] and Wolf specifies just how early. Recent research on Taiwanese divorce rates and fertility show that dwelling within the same household before age three is powerfully associated with eventual marital problems. Other data Wolf brings in, such as those on co-residents of Israeli kibbutzim and on Arab bint 'amm marriage partners who have been housemates from infancy, are broadly consistent with this $[8$, pp. 158-61]. Finally, Chinese data give convincing evidence that it is the younger partner who experiences the aversion [8, pp. 167-8].

We can scale several of our sample cultures regarding the earliest age at which intended partners live together and, in some of those cultures, we can also find evidence of aversion to sexual intimacy. First, girls among southeast Chinese were often just infants and toddlers when they moved in to their future husbands' homes. Aversion appears to have been common between such partners. High divorce rates provide one kind of evidence of this (a Taiwanese study showed that $24.2 \%$ of sim-pua marriages end in divorce, cf., $1.2 \%$ of "major" marriages); fertility is reduced by $31 \%$; and, in one community, it was found that sim-pua wives were three times more likely to have affairs than other married women in their region [8, pp. 182-3; 13, p. 161].

Next come the Paliyans and Garo. Junior partners among Paliyans were usually brought in at age five to ten (the youngest, an adopted girl, was still an infant) and there were signs of sexual aversion. Fertility in pedogamous Paliyan couples dropped almost as much as among Chinese with minor marriages, and one young woman repeatedly rejected her husband's sexual advances. We should recall, however, the durability of pedogamous unions among Paliyans. As for the Garo marriages which Burling studied, two out of eight of the jikgite were immature (one being of unspecified age, the other about eight). The same proportion of males (2/8) were said to experience problems consummating unions with their "young wives," which, in their way of thinking, made affairs a likely and problematic outcome for their jikgite. Although they do so in different ways, Paliyan and Garo data, like information on the Chinese, suggest that lengthy, immediate association with a child or preadolescent can create a relationship enough like an actual primary relationship to disrupt marital relations $[18,19]$.

There was considerable variation in the marriage ages of Tibetans, Kaingang, Hima, Diné, and possibly also Vellala. Although many of the Tibetans with plural marriages were at least in their teens at the onset of their association with partners, Tibetan spouses sometimes had big age differences and Kawakita gave no information on age of those entering chamadung unions. Kaingang were of similarly diverse ages. Several of the younger partners were said to be mature, yet one proposal of adoption then marriage concerned an elevenyear-old. Hima varied as well, with some youthful partners being of marriage age and others being viewed as somewhat short of sexual capability. A safe summary of these five cultures would be that most, if not all, cross-generational arrangements involved young people who were well past early childhood. And, no evidence was presented of difficulties due to feelings of engaging in incest.

Wadadika and Marquesans appear to have been of marriage age or old enough to be courted when co-residence began and their cross-generational arrangements went into effect. Again, we have a lack of evidence that the marital and sexual practices were disruptive.

Based on studies of "major" and "minor" Chinese marriages, A. P. Wolf would say that southeast Chinese have the only one of our ten cultures in which couples are brought together early enough, prior to age three, for their relationships to be disrupted by feelings of aversion. Because only one Paliyan (and perhaps one Garo) union matches the timing of the Chinese, the extent to which pedogamous Paliyans and Garos exhibit symptoms of sexual aversion similar to those of the Chinese raises questions about conclusions derived from study of China alone. Perhaps it is due to cultural factors not considered by Wolf, but the fact remains that Paliyan and Garo co-residence with children and preadolescents has been associated with problematic marriages. What is more, Burling specifies that it is the senior Garo partner, not the junior one, who feels aversion to sex. This totally contradicts Wolf's Chinese-based conclusions. Further study is needed.

\section{Steps Toward Explanation}

Another matter requires attention. We have found signs of a rough trend in our sample: Earlier co-residence of partners has been associated with greater marital difficulties. How, then, could any of these cultures prescribe or permit such arrangements? Disadvantages such as infertility and divorce are not trivial, so there would have to have been significant factors at play to outweigh them. There may well have been.

For purposes of comparative description, above, the cultures were organized in terms of broad similarity of their marital and sexual arrangements. As we seek to account for 
the quasi-incestuous unions, another, very different and crosscutting classification suggests itself. In three cultures in which union with adopted or step-relatives was fairly common (southeast Chinese, Tibetan, and Hima), elders exerted regular and purposeful control over marriage and sex. They set up marriages of the young in ways that would keep resources together and help to ensure continued social or economic cooperation within the group. In the one case in which disadvantages of such unions were even discussed by ethnographers, we are told that Chinese elders appear to have been more explicitly aware of the practical advantages to them of the "minor" marriage than they were of any potential drawbacks [18, pp. 178-83].

In two cultures in which there was occasional sexual union with close affines (Garo and Karaikkat Vellala), certain aspects of social structure were rigid. Each of the cultures had a well-defined contingency arrangement for maintaining a tight and proper structure in the face of problems such as the death or the immaturity of a participant in a marriage. Garos acted so as to restore the established affinal links between lineages; Karaikkat Vellalas set up interim proxy arrangements to ensure timely consummation of a marriage. These were both attempts to maintain structure, or to minimize discrepancies between what Firth termed structure and organization [36]. Those in charge of the arrangements may have taken the stance that more was at stake than mere comfort (or fertility) of participants. Garo men, at least, were under pressure to cooperate and act responsibly.

Three cultures (Paliyans, Wadadika Paiute, and Kaingang) were those of foragers, and a fourth one (Diné) had a mixed economy in which foraging was an important component until the early $19^{\text {th }}$ century. These people have all had to be versatile to cope with small-sized pools of potential marriage partners, a problem aggravated by the displacements and epidemics of recent centuries. They have also been the kind of foragers who emphatically stressed the importance of maintaining individual autonomy [37, 38]. Their social systems were loosely structured and un-coercive, according individuals considerable latitude as to whom they married so long as their actions were acceptable to the direct participants. They exercised that latitude. Henry said of Kaingang that "they have no sense of social form" and "They have no pattern that will exclude one kind of relationship while permitting another. So their sexual relations show the same formlessness" [26, p. 33]. In the Paliyan case, no one would, or could, preach to others about marital irregularities. Did older people take advantage of this openness simply for personal pleasure? Were they erotic opportunists? To some extent, perhaps this was so. Among Kaingang, "however strongly the men and women may be linked together in a common household the charm of casual intrigues is too great for them to forego" [26, p. 42]. But, while pursuit of the erotic was one of the Paliyan goals, their actions as regards sex and marriage centered again and again on other practicalities. They sought children and they hoped to form harmonious partnerships. Their words and actions reveal harmony as being a pressing desideratum. In the view of many Paliyans -- so similar to the southeast Chinese view -- there were possibilities for long-term practical advantages when unions began pedogamously. The picture may look loose and chaotic, but the south Indian foragers actually sought stability and order amongst other goals. Along much the same lines, Henry noted that some Kaingang achieved lasting and "comfortable security" [26, p. 42] through their household arrangements.

Among Marquesans, sexual relations with affines appear to have been occasional, optional, and surreptitious; they are spoken of as being "stolen" rather than being legitimate. The Marquesan case stands alone in these regards. Given the Marquesans' diverse institutionalized uses of sexual stimulation and intercourse from childbirth on [33], given our inability to estimate the actual incidence of sexual contact with affines, and given the opacity of key Marquesan motives and decisions, their pattern of affairs is probably best regarded as both distinctive and beyond simple explanation at this time.

Traditions of marital and sexual union with step- and adopted primary relatives have several different forms and these are to some extent understandable in their cultural contexts. Three provisional explanations allow us to begin to make sense of nine of the ten cases. As all are systems in which pragmatic interests of elders, structural rigidities, or relative freedom plus a quest for erotic delight and social stability figure heavily in the choosing of partners, each type of system appears to have provided incentives for action or forceful pressure to such a degree that people could overlook potential disadvantages to the resulting unions.

\section{CONCLUSIONS}

This paper has examined ten quasi-incestuous marital and sexual arrangements which anthropologists in the past have usually been content to deal with culture by culture. Looking at them comparatively, however, we have ascertained that some of the arrangements exhibit broad similarities as problem solving devices, and a few of them share some serious and measurable disadvantages. In bringing out these positive and negative commonalities, the exercise has made such unions more understandable, it has brought us closer to their actual explanation, and it has contributed to long-term refinement of incest theory.

Further study is clearly necessary, but our knowledge of each culture will be deepened if we can achieve a better sense of the pressures for and against the various kinds of union in the respective systems. For instance, the possible instrumentality of much pedogamy raises the question as to whether foragers in the sample are undertaking such marriages as a subtle way of manipulating the behavior of others in societies in which the norm may be principled anarchy.

The three provisional modal types of quasi-incest we have identified are clearly different from one another. Although we are far from being able to say that the unions have been explained, a step in that direction has definitely been made.

Small bodies of Paliyan and Garo data suggest that marrying those who have been members of one's household since they were children or preadolescents leads some participants to experience sexual aversion -- an outcome Wolf expects to be associated only with co-residence of the couple prior to the junior partner reaching age three. The apparent discrepancy between Southeast Chinese and particular other peoples suggests that additional (perhaps cultural) factors may have to be included in our modeling of incest aversion. If further work shows this to be so, it would retrieve the 
study of incest avoidance from strict universalists and it might serve to engender greater cultural anthropological interest in the subject.

\section{ACKNOWLEDGEMENTS}

This research was supported, during 1962-1964, by both a fellowship from the Ford Foundation, administered by the Joint Committee of SSRC-ACLS and an extension of that fellowship; during 1978, by a Faculty Summer Fellowship from the Research Council of the University of MissouriColumbia and a travel grant from the American Institute of Indian Studies; and, during 1991, by a University of Missouri departmental research leave. I express my appreciation for the patience and assistance of countless Paliyan consultants, Finally, I thank Kelly Pawelski-Jones and Michael C. Robbins for helpful reactions to particular ideas and arguments.

\section{REFERENCES}

[1] Gardner PM. The Paliyans. In: Bicchieri MG, Ed. Hunters and Gatherers Today. New York: Holt, Rinehart and Winston 1972; pp. 404-47.

[2] Gardner PM. Pressures for Tamil Propriety in Paliyan Social Organization. In: Ingold T, Riches D, Woodburn J, Eds. Hunters and Gatherers 1: History, Evolution and Social Change. Oxford: Berg 1988; pp. 91-106.

[3] Murdock GP. Social Structure. NY: Macmillan 1949.

[4] Aberle D, Bronfenbrenner U, Hess EH, et al. The incest taboo and the mating of animals. Am Anthropol 1963; 65(2): 253-65.

[5] Burton RV. Folk theory and the incest taboo. Ethos 1973; 1(4): 504-16.

[6] Fox R. The Red Lamp of Incest. NY: Dutton 1980.

[7] Durham WH. Coevolution: Genes, Culture, and Human Diversity. Stanford: Stanford University Press 1991.

[8] Wolf AP. Westermark redivivus. Annu Rev Anthropol 1993; 22: 157-75.

[9] Turner JH, Maryanski A. Incest: Origins of the Taboo. London: Paradigm 2005.

[10] Gardner PM. Dimensions of subsistence foraging in south India. Ethnology 1993; 32(2): 109-44.

[11] Gardner PM. Bicultural versatility as a frontier adaptation among Paliyan foragers of south India. Lewiston, NY: Edwin Mellen Press 2000.

[12] Kolenda PM. Regional Differences in Indian Family Structure. In: Crane R, Ed. Regions and Regionalism in South Asian Studies: an exploratory study. Durham: Duke University Program in Comparative Studies on Southern Asia 1967; pp. 147-226.

[13] Gardner PM. Respect and non-violence among recently sedentary Paliyan foragers. J R Anthropol Inst 2000; (N.S.) 6(2): 215-36.
[14] Dahman F. The Paliyans, a hill tribe of the Palni Hills (south India). Anthropos 1908; 3(1): 19-31.

[15] Nabokov V. The Enchanter. New York: GP Putnam's Sons 1986

[16] Nabokov V. Lolita. Paris: Olympia Press 1955.

[17] Wolf AP. Adopt a daughter-in-law, marry a sister: a Chinese solution to the problem of the incest taboo. Am Anthropol 1968; 70(5): 864-74.

[18] Wolf M. Women and the Family in Rural Taiwan. Stanford: Stanford University Press 1972.

[19] Burling R. Rengsanggri: Family and Kinship in a Garo Village. Philadelphia: University of Pennsylvania Press 1963.

[20] Ekvall RB. Fields on the Hoof: Nexus of Tibetan Nomadic Pastoralism. New York: Holt, Rinehart and Winston 1968.

[21] Kawakita J. Ethno-geographical Observations on the Nepal Himalaya. In: Kihara H, Ed. Peoples of Nepal Himalaya, Kyoto: Kyoto University Flora and Fauna Research Society 1957; vol. 3: pp. 1362.

[22] Goldstein MG. Stratification, polyandry, and family structure in central Tibet. Southwest J Anthropol 1971; 27(1): 64-74.

[23] Whiting BB. Paiute Sorcery. New York: Viking Fund Publications in Anthropology, No. 151950.

[24] Shepardson M, Hammond B. The Navajo Mountain Community: Social Organization and Kinship Terminology. Berkeley: University of California Press 1970.

[25] Aberle DF. Navaho. In: Schneider DM, Gough K, Eds. Matrilineal kinship. Berkeley: University of California Press 1961; pp. 96-201.

[26] Henry J. Jungle People: A Kaingang Tribe of the Highlands of Brazil. New York: JJ Augustin 1941.

[27] Elam Y. The Social and Sexual Roles of Hima Women: A Study of Nomadic Cattle Breeders in Nyabushozi County, Ankole, Uganda. Manchester: Manchester University Press 1973.

[28] Seligman CG, Seligman BZ. Pagan Tribes of the Nilotic Sudan. London: Routledge and Kegan Paul 1932.

[29] Thurston E. Ethnographic notes in Southern India. Madras: Government Press 1906.

[30] Thurston E, Rangachari K. Tribes and Castes of Southern India, Madras: Government Press 1909; vol. 4.

[31] Thurston E, Rangachari K. Tribes and Castes of Southern India, Madras: Government Press 1909; vol. 3.

[32] Handy ESC. The Native Culture in the Marquesas. Honolulu: BP Bishop Mus Bull, No. 91923.

[33] Linton R. Marquesan Culture. In: Kardiner A, Ed. The Individual and His Society: the Psychodynamics of Primitive Social Organization. New York: Columbia University Press 1939; pp. 137-96.

[34] Morgan LH. Ancient Society. Chicago: CH Kerr 1877.

[35] Westermarck E. The History of Human Marriage. London: Macmillan 1894.

[36] Firth R. Elements of Social Organization. London: Watts 1951.

[37] Gardner PM. Symmetric respect and memorate knowledge: the structure and ecology of individualistic culture. Southwest J Anthropol 1966; 22(4): 389-415.

[38] Gardner PM. Foragers' pursuit of individual autonomy. Curr Anthropol 1991; 32(5): 543-72. 